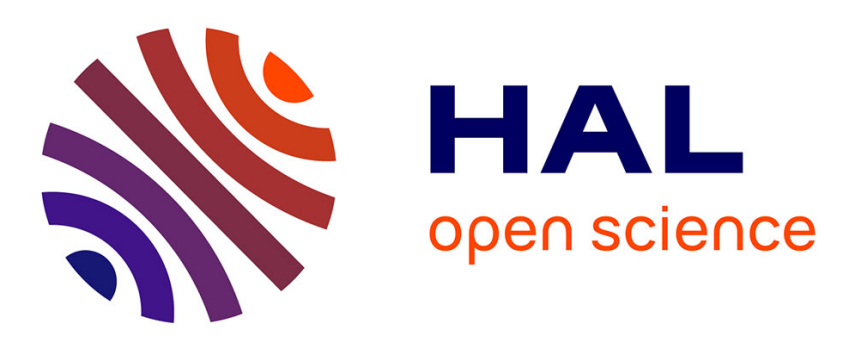

\title{
Protonated ions as systemic trapping agents for noble gases: From electronic structure to radiative association
}

O. Ozgurel, F. Pauzat, J. Pilme, Y. Ellinger, M.-C. Bacchus-Montabonel, O. Mousis

\section{- To cite this version:}

O. Ozgurel, F. Pauzat, J. Pilme, Y. Ellinger, M.-C. Bacchus-Montabonel, et al.. Protonated ions as systemic trapping agents for noble gases: From electronic structure to radiative association. Journal of Chemical Physics, 2017, 147 (13), pp.134305. 10.1063/1.4994630 . hal-01626185

\section{HAL Id: hal-01626185 \\ https://hal.sorbonne-universite.fr/hal-01626185}

Submitted on 31 Oct 2017

HAL is a multi-disciplinary open access archive for the deposit and dissemination of scientific research documents, whether they are published or not. The documents may come from teaching and research institutions in France or abroad, or from public or private research centers.
L'archive ouverte pluridisciplinaire HAL, est destinée au dépôt et à la diffusion de documents scientifiques de niveau recherche, publiés ou non, émanant des établissements d'enseignement et de recherche français ou étrangers, des laboratoires publics ou privés. 


\section{Protonated ions as systemic trapping agents for noble gases: From electronic structure to radiative association}

O. Ozgurel, F. Pauzat, J. Pilmé, Y. Ellinger, M.-C. Bacchus-Montabonel, and O. Mousis

Citation: The Journal of Chemical Physics 147, 134305 (2017);

View online: https://doi.org/10.1063/1.4994630

View Table of Contents: http://aip.scitation.org/toc/jcp/147/13

Published by the American Institute of Physics

\section{Articles you may be interested in}

Investigation of the two- and three-fragment photodissociation of the tert-butyl peroxy radical at $248 \mathrm{~nm}$ The Journal of Chemical Physics 147, 134304 (2017); 10.1063/1.4994713

Detection and structural characterization of nitrosamide $\mathrm{H}_{2} \mathrm{NNO}$ : A central intermediate in de $\mathrm{NO}_{x}$ processes The Journal of Chemical Physics 147, 134301 (2017); 10.1063/1.4992097

Experimental and theoretical studies of the reactions of ground-state sulfur atoms with hydrogen and deuterium

The Journal of Chemical Physics 147, 134302 (2017); 10.1063/1.4991418

Communication: A hydrogen-bonded difluorocarbene complex: Ab initio and matrix isolation study The Journal of Chemical Physics 147, 131102 (2017); 10.1063/1.4999772

The aug-cc-pVnZ-F12 basis set family: Correlation consistent basis sets for explicitly correlated benchmark calculations on anions and noncovalent complexes

The Journal of Chemical Physics 147, 134106 (2017); 10.1063/1.4998332

Connections between variation principles at the interface of wave-function and density-functional theories The Journal of Chemical Physics 147, 134107 (2017); 10.1063/1.4985883

\section{AlP| The Journal of Chemical Physics}

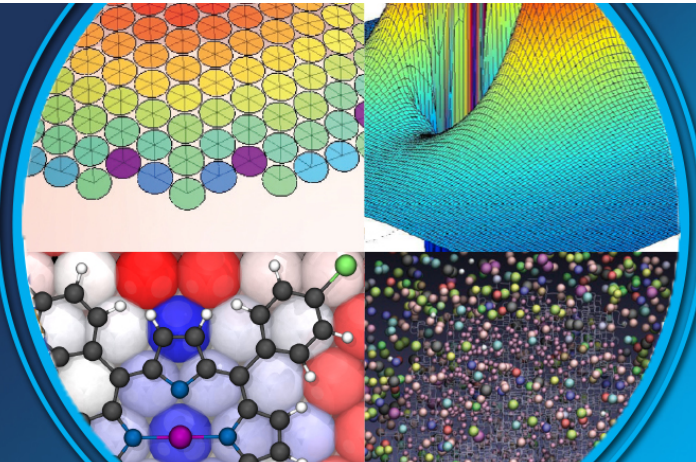




\title{
Protonated ions as systemic trapping agents for noble gases: From electronic structure to radiative association
}

\author{
O. Ozgurel, ${ }^{1}$ F. Pauzat, ${ }^{1, a)}$ J. Pilmé,${ }^{1}$ Y. Ellinger,${ }^{1}$ M.-C. Bacchus-Montabonel, ${ }^{2}$ \\ and $\mathrm{O}$. Mousis ${ }^{3}$ \\ ${ }^{1}$ Sorbonne Universités, UPMC Univ. Paris 06, UMR-CNRS 7616, Laboratoire de Chimie Théorique, \\ F-75005 Paris, France \\ ${ }^{2}$ Institut Lumière Matière, UMR5306 Université Lyon1-CNRS, Université de Lyon, \\ F-69622 Villeurbanne, France \\ ${ }^{3}$ Aix Marseille Université, CNRS, LAM (Laboratoire d'Astrophysique de Marseille) UMR 7326, \\ 13388 Marseille, France
}

(Received 6 July 2017; accepted 19 September 2017; published online 5 October 2017)

\begin{abstract}
The deficiencies of argon, krypton, and xenon observed in the atmosphere of Titan as well as anticipated in some comets might be related to a scenario of sequestration by $\mathrm{H}_{3}^{+}$in the gas phase at the early evolution of the solar nebula. The chemical process implied is a radiative association, evaluated as rather efficient in the case of $\mathrm{H}_{3}^{+}$, especially for krypton and xenon. This mechanism of chemical trapping might not be limited to $\mathrm{H}_{3}^{+}$only, considering that the protonated ions produced in the destruction of $\mathrm{H}_{3}^{+}$by its main competitors present in the primitive nebula, i.e., $\mathrm{H}_{2} \mathrm{O}, \mathrm{CO}$, and $\mathrm{N}_{2}$, might also give stable complexes with the noble gases. However the effective efficiency of such processes is still to be proven. Here, the reactivity of the noble gases $\mathrm{Ar}, \mathrm{Kr}$, and $\mathrm{Xe}$, with all protonated ions issued from $\mathrm{H}_{2} \mathrm{O}, \mathrm{CO}$, and $\mathrm{N}_{2}$, expected to be present in the nebula with reasonably high abundances, has been studied with quantum simulation method dynamics included. All of them give stable complexes and the rate coefficients of their radiative associations range from $10^{-16}$ to $10^{-19} \mathrm{~cm}^{3} \mathrm{~s}^{-1}$, which is reasonable for such reactions and has to be compared to the rates of $10^{-16}$ to $10^{-18} \mathrm{~cm}^{3} \mathrm{~s}^{-1}$, obtained with $\mathrm{H}_{3}^{+}$. We can consider this process as universal for all protonated ions which, if present in the primitive nebula as astrophysical models predict, should act as sequestration agents for all three noble gases with increasing efficiency from Ar to Xe. Published by AIP Publishing. https://doi.org/10.1063/1.4994630
\end{abstract}

\section{INTRODUCTION}

The problem of the noble gases' deficiency observed in Titan's atmosphere ${ }^{1}$ has led to tentative explanations through several models, none of them fully satisfactory. Theoretical quantum chemistry, with high level ab initio simulations, demonstrated that, at least from a thermodynamic point of view, $\mathrm{H}_{3}^{+}$is able to act as a trap for noble gases by forming complexes in the gas phase. ${ }^{2,3}$ The coupling of these results with those of an elaborate model giving the abundance profile of $\mathrm{H}_{3}^{+}$in the conditions of the cooling proto-planetary disks ${ }^{4-6}$ led to the conclusion that $\mathrm{H}_{3}^{+}$might be abundant enough in the outer protosolar nebula to trap, at least $\mathrm{Xe}$ and $\mathrm{Kr}$, prior to their condensation epochs, implying that their abundances should be solar in Saturn's current atmosphere and below the observational limit in Titan. The same scenario predicts that comets agglomerated from ices formed at high heliocentric distances might also be depleted in $\mathrm{Kr}$ and $\mathrm{Xe}$.

In the astrophysical models, the crucial point is the accurate determination of the abundance of $\mathrm{H}_{3}^{+}$, which implies evaluating not only its production but also its destruction along the cooling evolution of the proto-planetary disk. That is why a complete modeling should take into account the molecules

a)Electronic mail: pauzat@lct.jussieu.fr. able to react with $\mathrm{H}_{3}^{+}$during this period and the evolution of their abundances with time.

From a chemical point of view, when we looked at the main destructive agent for $\mathrm{H}_{3}^{+}$, i.e., $\mathrm{H}_{2} \mathrm{O}$, we found that the result of the destructive reaction, i.e., $\mathrm{H}_{3} \mathrm{O}^{+}$, could also act as a trapping agent for the noble gases, leading to chemically stable complexes ${ }^{6}$ via radiative associations with the noble gases. Then we have to consider the possibility of a similar behavior for all protonated ions, among which those issued from the other main destructors of $\mathrm{H}_{3}^{+}$present in the environment. Nevertheless, to be conclusive, it implies performing a complete quantitative study of these radiative associations and in particular to evaluate reliable rate constants of these reactions which belong to a category usually considered not to be very efficient.

In the solar nebula, the $\mathrm{H}_{3}^{+}$formed can be destroyed by the reactions with the most abundant molecules of the gas phase, namely, $\mathrm{H}_{2} \mathrm{O}, \mathrm{CO}$, and $\mathrm{N}_{2} .{ }^{6}$ In a steady state, formation and destruction rates balance each other, but when the solar nebula cools down, the destructive molecules do not remain in the gas phase (the upper limit being a local temperature of $150 \mathrm{~K}$ ), being trapped themselves as clathrates or simply condensing, and the balance has to be adjusted. However, if these molecules are reacting with $\mathrm{H}_{3}^{+}$to give ions with a significant capability for trapping the noble gases, most adjustments of the density of $\mathrm{H}_{3}^{+}$could be avoided, each $\mathrm{H}_{3}^{+}$destroyed being replaced 
by another trapping ion. This can be argued safely as long as the trapping capabilities are more or less equivalent. In these reactions, $\mathrm{H}_{3}^{+}$plays the role of a universal proton donor; the reactions implied in such a scheme are

$$
\begin{gathered}
\mathrm{H}_{3}^{+}+\mathrm{H}_{2} \mathrm{O} \rightarrow \mathrm{H}_{3} \mathrm{O}^{+}+\mathrm{H}_{2}, \\
\mathrm{H}_{3}^{+}+\mathrm{CO} \rightarrow \mathrm{HCO}^{+}+\mathrm{H}_{2}, \\
\mathrm{H}_{3}^{+}+\mathrm{CO} \rightarrow \mathrm{HOC}^{+}+\mathrm{H}_{2}, \\
\mathrm{H}_{3}^{+}+\mathrm{N}_{2} \rightarrow \mathrm{N}_{2} \mathrm{H}^{+}+\mathrm{H}_{2} .
\end{gathered}
$$

All these ions are well-known and ubiquitous in astrophysical objects. Looking at the reported original detections in the interstellar medium (ISM) and circumstellar envelopes, we can cite ${ }^{7} \mathrm{HCO}^{+}$first seen in 1970 and confirmed five years later, ${ }^{8} \mathrm{HN}_{2}^{+},{ }^{9,10}$ and $\mathrm{HOC}^{+} .{ }^{11,12}$ We can also mention further detections of $\mathrm{HCO}^{+},{ }^{13} \mathrm{HN}_{2}^{+},{ }^{14}$ and $\mathrm{HOC}^{+} .{ }^{15}$ The detection of $\mathrm{H}_{3} \mathrm{O}^{+}$has also been reported in the ISM. ${ }^{16,17}$ Moreover, all these reactions [Eqs. (1)-(4)] are known to be thermodynamically (exothermic) and dynamically efficient (http://www.rate99.co.uk/).

In the solar system, the $\mathrm{H}_{3}^{+}$emission has been recorded towards the auroral zone of Jupiter, soon followed by its detection in giant planets Saturn and Uranus, ${ }^{18}$ whereas it took ten more years to succeed in the detection of $\mathrm{H}_{3}^{+}$and its isotopologs 19,20 in the ISM.

The role of $\mathrm{H}_{3}^{+}$itself, as a possible trapping agent for noble gases, has already been fully investigated, ${ }^{21}$ but one has to be aware that till now this scenario has never been quantified for any other trapping agent beyond a static description of the trapping processes.

In a general way, two radiative association processes would lead to the $\mathrm{XHY}^{+}$complex (with $\mathrm{X}=\mathrm{Ar}, \mathrm{Kr}, \mathrm{Xe}$ and $\mathrm{Y}$ $=\mathrm{H}_{2} \mathrm{O}, \mathrm{CO}, \mathrm{N}_{2}$ ), namely,

$$
\mathrm{X}+\mathrm{YH}^{+} \rightarrow \mathrm{XHY}^{+}+\mathrm{h} v
$$

and

$$
\mathrm{XH}^{+}+\mathrm{Y} \rightarrow \mathrm{XHY}^{+}+\mathrm{h} v
$$

Because the concentrations of the $\mathrm{XH}^{+}$species are so low (no detection has been reported apart from that of ${ }^{36} \mathrm{ArH}^{+}$in a supernova remnant known as the Crab nebula), ${ }^{22}$ the formation of the $\mathrm{XHY}^{+}$complexes via [Eq. (6)] is assumed to be negligible and therefore the only route to be considered is the radiative association [Eq. (5)].

\section{COMPUTATIONAL STRATEGY}

To reduce the length of the story, only a brief overview of the key theoretical points of the static and dynamic aspects of this research is presented (see Appendices for more details). In the present study, we employ a fully $a b$ initio approach, from the calculations of the reactive potential surfaces to the determination of the corresponding radiative association rate constants.

Concerning the thermodynamic part, all treatments belong to the $a b$ initio coupled cluster area, i.e., CCSD and CCSDT associated with a correlation consistent basis set cc-pVQZ and its augmented versions (aug-) of increasing flexibility in the valence shell. The calculations were performed with the G09 version of the Gaussian package. ${ }^{23}$

(1) The first task is to determine the structure of the complexes. All stationary points were optimized and the stability conditions were verified by a vibrational analysis.

(2) In order to get reliable geometries and stabilities, the potential energy surface around the minima had to be reconstructed to correct the bias introduced by the artificial stabilization of the energy of such weakly bound complexes due to the fact that the interacting fragments borrow each other's basis sets to lower their energies. This artifact is known as the basis set superposition error (BSSE). It was corrected here using the counterpoise method, ${ }^{24}$ for all points of the re-optimization of the geometrical parameters implied in the description of the two entities interacting in the complex. The difficulty is to determine the fragments to be considered when several separations are possible, a situation we have already faced with the complexes between $\mathrm{H}_{3}^{+}$and the noble gases. Usually we can refer to those of the lowest energy dissociation. However, when it was unclear which separation to use, we relied on a topological analysis (see Sec. IV and Appendix A) of the complex to get the partitioning of the physical space into well-defined interacting fragments.

For the dynamic part, the radiative association calculations are done in a pseudo-diatom approximation (see Appendix B). We relied on the previous computational experiments $^{21}$ performed for the rate constants of the radiative associations of argon with $\mathrm{H}_{3}^{+}$.

\section{STRUCTURE AND STABILITY OF THE PROTONATED IONS}

Taking $\mathrm{H}_{3}^{+}$as a reference for the capture of noble gases $\mathrm{X}$, we report some preceding results for the structure (Fig. 1) and binding energies (Table I) of the $\mathrm{X}-\mathrm{H}_{3}^{+}$complexes. $^{2}$

For all $\mathrm{X}-\mathrm{H}_{3}^{+}$complexes, the most stable geometry is that of $\mathrm{C}_{2 v}$ symmetry in which $\mathrm{X}$ points to an apex of the $\mathrm{H}_{3}^{+}$triangle (Fig. 1); this occurs at all levels of theory.

The convergence of the computational methods used allows us to consider the energetic calculations reliable by $1 \%-2 \%$ when reaching the CCSDT/aug-cc-pVQZ level.

\section{A. The structures of protonated ions with noble gases $[X-i o n-H]^{+}(X=A r, K r$, and $\mathrm{Xe})$}

All complexes, whatever the noble gas, are structurally similar (Fig. 2). The geometries presented in Table II show that the BSSE corrections, which could lead to changes of $1 \%$ $2 \%$ in the most influenced bond lengths, cannot be escaped.

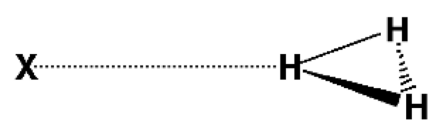

FIG. 1. The stable structure of $\mathrm{X} \cdots \mathrm{H}_{3}^{+}$for $\mathrm{X}=\mathrm{Ar}, \mathrm{Kr}$, and $\mathrm{Xe}$. 
TABLE I. Stabilities of the $\mathrm{X} \cdots \mathrm{H}_{3}^{+}$complexes ( $\left.\mathrm{kcal} / \mathrm{mol}\right)$, including harmonic zero point energies ${ }^{\mathrm{a}}$ and BSSE correction, related to reactions $\mathrm{R} 1$ and R2. ${ }^{\text {b }}$ Basis sets: /Q = cc-pVQZ; /aug-Q = aug-cc-pVQZ.

\begin{tabular}{lcccccc}
\hline \hline Complex & $\mathrm{Ar} \cdots$ & $\mathrm{H}_{3}^{+}$ & $\mathrm{Kr} \cdots$ & $\mathrm{H}_{3}^{+}$ & $\mathrm{Xe} \cdots$ & $\mathrm{H}_{3}^{+}$ \\
Reactions & $\mathrm{R} 1$ & $\mathrm{R} 2$ & $\mathrm{R} 1$ & $\mathrm{R} 2$ & $\mathrm{R} 1$ & $\mathrm{R} 2$ \\
\hline $\mathrm{CCSD}(\mathrm{T}) / \mathrm{Q}$ & 7.27 & 16.01 & 13.03 & 8.60 & 23.22 & 2.93 \\
$\mathrm{CCSD}(\mathrm{T}) /$ aug-Q & 7.35 & 16.16 & 13.50 & 8.54 & 23.64 & 2.78 \\
\hline \hline
\end{tabular}

${ }^{\mathrm{a} C \text { Calculated at level CCSD(T)/Q. }}$

${ }^{\mathrm{b}} \mathrm{R} 1=\mathrm{X} \cdots \mathrm{H}_{3}^{+} \rightarrow \mathrm{X}+\mathrm{H}_{3}^{+}$and $\mathrm{R} 2=\mathrm{X} \cdots \mathrm{H}_{3}^{+} \rightarrow \mathrm{XH}^{+}+\mathrm{H}_{2}$.

This is especially true if spectroscopic data are to be calculated in order to help with the detection of such species. It should be emphasized that contrary to a posteriori corrections of the energy of the equilibrium structures, the optimization procedure reported here are carried out including an a priori correction of the BSSE artifact for all the geometrical parameters defining the molecular structures.

\section{$B$. The binding energies of protonated ions with noble gases [X-ion- $]^{+}(\mathrm{X}=\mathrm{Ar}, \mathrm{Kr}$, and $\mathrm{Xe})$}

The evolutions of the complex stabilities within the series $\mathrm{Ar} \rightarrow \mathrm{Kr} \rightarrow$ Xe present the same trend: as for the $\mathrm{XH}_{3}^{+}$complexes, the stability decreases in the R1 fragmentation from Ar to Xe, whereas it increases for R2 (see Table III).

Looking at the energetic balance, one has the following:

(1) For $\mathrm{X}-\mathrm{H}_{3} \mathrm{O}^{+}$, we found that, contrary to the reference $\mathrm{XH}_{3}^{+}$, all complexes prefer a common dissociative process leading to $\mathrm{X}+\mathrm{H}_{3} \mathrm{O}^{+}$whatever the noble gas. The point to be noted is that, when comparing the stability values in Tables III and I, it is obvious that each $\mathrm{H}_{3} \mathrm{O}^{+}$ ion issued from the destruction of $\mathrm{H}_{3}^{+}$by $\mathrm{H}_{2} \mathrm{O}$ in the gas

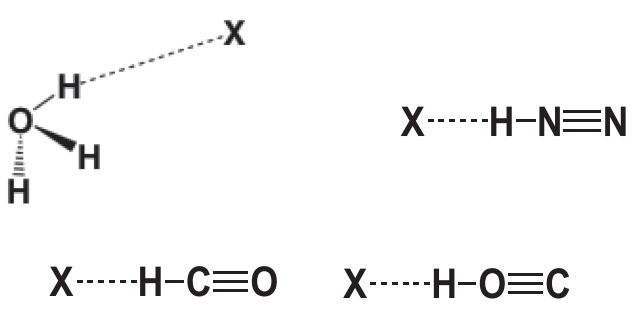

FIG. 2. Equilibrium structures of the $\mathrm{X}$-protonated ions with $\mathrm{X}=\mathrm{Ar}, \mathrm{Kr}$, and $\mathrm{Xe}$.

phase should be able to play an almost equivalent role in the capture process of noble gases.

(2) For X-HCO ${ }^{+}$and $\mathrm{X}-\mathrm{HOC}^{+}$, one has two different situations although they are isomers whose difference is only due to the attachment of the proton to one or the other extremity of the $\mathrm{CO}$ diatomic species. The case of $\mathrm{XHCO}^{+}$is very close to $\mathrm{X}-\mathrm{H}_{3} \mathrm{O}^{+}$: for all $\mathrm{X}, \mathrm{R} 1$ is the preferred dissociative channel with similar energies increasing from Ar to Xe. The case of $\mathrm{XHOC}^{+}$is different and closer to $\mathrm{XH}_{3}^{+}$. If the $\mathrm{R} 1$ dissociation is favored for Ar, it is the R2 dissociation that is favored for Xe. The case of $\mathrm{Kr}$ is very sensitive to the method used. Indeed, $\mathrm{X}-\mathrm{HOC}^{+}$dissociates following the $\mathrm{R} 1$ route for Density Functional Theory (DFT) but following the R2 route for MP2 (not shown here). However, higher levels of theory, as CCSD and CCSDT, agree on this complex being intermediate between two cluster structures as shown below in the topological analysis of the electronic structure of this complex. Finally, confronting the values obtained for both complex families shows that their stabilities are equivalent to $\mathrm{XH}_{3}^{+}$reported in Table I $(7.3,8.5$, $2.8 \mathrm{kcal})$, indicating that the trapping power of $\mathrm{HCO}^{+}$

TABLE II. Raw and BSSE-optimized equilibrium geometries ${ }^{\mathrm{a}}$ of the $\mathrm{X} \cdots$ ion $^{+}$complexes $(\mathrm{X}=\mathrm{Ar}, \mathrm{Kr}$, and $\mathrm{Xe})$ and rotational constants in $\mathrm{GHz}$ at the CCSD(T)/cc-pVQZ level of theory and dipole moments in Debye at CCSD.

\begin{tabular}{|c|c|c|c|c|c|c|c|c|c|c|c|c|}
\hline \multirow[t]{2}{*}{ Complex } & \multicolumn{4}{|c|}{ Raw-optimized geometry } & \multicolumn{4}{|c|}{ BSSE-optimized geometry } & \multirow[t]{2}{*}{ A } & \multirow[t]{2}{*}{ B } & \multirow[t]{2}{*}{$\mathrm{C}$} & \multirow[t]{2}{*}{$\mu$} \\
\hline & $\mathrm{X}-\mathrm{H}_{\mathrm{X}}$ & $\mathrm{H}_{\mathrm{X}}-\mathrm{O}$ & $\mathrm{H}_{\mathrm{O}}-\mathrm{O}$ & $\mathrm{H}_{\mathrm{O}}-\mathrm{O}-\mathrm{H}_{\mathrm{O}}$ & $\mathrm{X}-\mathrm{H}_{\mathrm{X}}$ & $\mathrm{H}_{\mathrm{X}}-\mathrm{O}$ & $\mathrm{H}_{\mathrm{O}}-\mathrm{O}$ & $\mathrm{H}_{\mathrm{O}}-\mathrm{O}-\mathrm{H}_{\mathrm{O}}$ & & & & \\
\hline $\mathrm{Ar} \cdots \mathrm{H}_{3} \mathrm{O}^{+}$ & 2.053 & 0.991 & 0.974 & 111.21 & 2.068 & 0.990 & 0.974 & 111.29 & 319.6 & 4.175 & 4.140 & 8.3 \\
\hline $\mathrm{Kr} \cdots \mathrm{H}_{3} \mathrm{O}^{+}$ & 2.151 & 0.997 & 0.974 & 111.16 & 2.187 & 0.995 & 0.974 & 111.22 & 318.2 & 3.215 & 3.195 & 10.2 \\
\hline \multirow[t]{2}{*}{$\mathrm{Xe} \cdots \mathrm{H}_{3} \mathrm{O}^{+}$} & 2.293 & 1.005 & 0.974 & 110.87 & 2.340 & 1.002 & 0.974 & 110.95 & 318.3 & 2.721 & 2.706 & 10.9 \\
\hline & $\mathrm{X}-\mathrm{H}_{\mathrm{X}}$ & $\mathrm{H}_{\mathrm{X}}-\mathrm{C}$ & $\mathrm{C}-\mathrm{O}$ & & $\mathrm{X}-\mathrm{H}_{\mathrm{X}}$ & $\mathrm{H}_{\mathrm{X}}-\mathrm{C}$ & $\mathrm{C}-\mathrm{O}$ & & & & & \\
\hline $\mathrm{Ar} \cdots \mathrm{HCO}^{+}$ & 2.110 & 1.112 & 1.110 & & 2.133 & 1.111 & 1.110 & & & 1.973 & 1.973 & 5.3 \\
\hline $\mathrm{Kr} \cdots \mathrm{HCO}^{+}$ & 2.199 & 1.120 & 1.110 & & 2.239 & 1.118 & 1.110 & & & 1.468 & 1.468 & 8.0 \\
\hline \multirow[t]{2}{*}{$\mathrm{Xe} \cdot \cdots \mathrm{HCO}^{+}$} & 2.316 & 1.135 & 1.111 & & 2.372 & 1.130 & 1.110 & & & 1.244 & 1.244 & 9.2 \\
\hline & $\mathrm{X}-\mathrm{H}_{\mathrm{X}}$ & $\mathrm{H}_{\mathrm{X}}-\mathrm{O}$ & $\mathrm{O}-\mathrm{C}$ & & $\mathrm{X}-\mathrm{H}_{\mathrm{X}}$ & $\mathrm{H}_{\mathrm{X}}-\mathrm{O}$ & $\mathrm{O}-\mathrm{C}$ & & & & & \\
\hline $\mathrm{Ar} \cdots \mathrm{HOC}^{+}$ & 1.695 & 1.073 & 1.153 & & 1.707 & 1.071 & 1.153 & & & 2.724 & 2.724 & 3.3 \\
\hline $\mathrm{Kr} \cdots \mathrm{HOC}^{+}$ & 1.737 & 1.135 & 1.146 & & 1.739 & 1.139 & 1.151 & & & 2.035 & 2.035 & 4.8 \\
\hline \multirow[t]{2}{*}{$\mathrm{Xe} \cdots \mathrm{HOC}^{+}$} & 1.648 & 1.579 & 1.142 & & 1.642 & 1.611 & 1.142 & & & 1.516 & 1.516 & 5.0 \\
\hline & $\mathrm{X}-\mathrm{H}_{\mathrm{X}}$ & $\mathrm{H}_{\mathrm{X}}-\mathrm{N}$ & $\mathrm{N}-\mathrm{N}$ & & $\mathrm{X}-\mathrm{H}_{\mathrm{X}}$ & $\mathrm{H}_{\mathrm{X}}-\mathrm{N}$ & $\mathrm{N}-\mathrm{N}$ & & & & & \\
\hline $\mathrm{Ar} \cdots \mathrm{HNN}^{+}$ & 1.881 & 1.076 & 1.096 & & 1.893 & 1.075 & 1.096 & & & 2.383 & 2.383 & 4.2 \\
\hline $\mathrm{Kr} \cdots \mathrm{HNN}^{+}$ & 1.950 & 1.099 & 1.096 & & 1.991 & 1.092 & 1.096 & & & 1.764 & 1.764 & 6.4 \\
\hline $\mathrm{Xe} \cdot \cdots \mathrm{HNN}^{+}$ & 2.049 & 1.142 & 1.097 & & 2.057 & 1.145 & 1.097 & & & 1.508 & 1.508 & 7.1 \\
\hline
\end{tabular}

a Bond lengths in $\AA$; angles in deg. 
TABLE III. Stabilities of the $\mathrm{X} \cdots \mathrm{H}_{3}^{+}$complexes $(\mathrm{kcal} / \mathrm{mol})$, including harmonic zero point energies ${ }^{\mathrm{a}}$ and BSSE correction, related to reactions $\mathrm{R} 1$ and R2. ${ }^{\mathrm{b}}$ Basis sets: /Q = cc-pVQZ; /aug-Q = aug-cc-pVQZ.

\begin{tabular}{|c|c|c|c|c|c|c|}
\hline \multirow{2}{*}{$\begin{array}{l}\text { Complex } \\
\text { Reactions }\end{array}$} & \multicolumn{2}{|c|}{$[\text { Ar-ion-H }]^{+}$} & \multicolumn{2}{|c|}{$[\mathrm{Kr} \text {-ion-H }]^{+}$} & \multicolumn{2}{|c|}{$[\text { Xe-ion-H }]^{+}$} \\
\hline & R1 & $\mathrm{R} 2$ & R1 & $\mathrm{R} 2$ & $\mathrm{R} 1$ & $\mathrm{R} 2$ \\
\hline \multicolumn{7}{|l|}{$[\text { ion- } \mathrm{H}]^{+}=\mathrm{H}_{3} \mathrm{O}^{+}$} \\
\hline $\operatorname{CCSD}(\mathrm{T}) / \mathrm{Q}$ & 4.24 & 78.47 & 5.80 & 67.19 & 7.85 & 52.53 \\
\hline $\operatorname{CCSD}(\mathrm{T}) /$ aug-Q & 4.43 & 77.55 & 6.00 & 65.84 & 8.12 & 50.76 \\
\hline \multicolumn{7}{|l|}{$[\text { ion- } \mathrm{H}]^{+}=\mathrm{HCO}^{+}$} \\
\hline $\operatorname{CCSD}(\mathrm{T}) / \mathrm{Q}$ & 4.31 & 54.54 & 5.81 & 43.21 & 7.99 & 28.66 \\
\hline $\operatorname{CCSD}(\mathrm{T}) /$ aug-Q & 4.53 & 54.78 & 5.73 & 42.71 & 8.26 & 28.04 \\
\hline \multicolumn{7}{|l|}{$[\text { ion- } \mathrm{H}]^{+}=\mathrm{HOC}^{+}$} \\
\hline $\operatorname{CCSD}(\mathrm{T}) / \mathrm{Q}$ & 10.82 & 23.70 & 15.16 & 15.21 & 23.60 & 6.92 \\
\hline $\operatorname{CCSD}(\mathrm{T}) / \mathrm{aug}-\mathrm{Q}$ & 10.90 & 23.86 & 15.47 & 15.16 & 24.59 & 7.07 \\
\hline \multicolumn{7}{|l|}{$[\text { ion-H }]^{+}=\mathrm{HNN}^{+}$} \\
\hline $\operatorname{CCSD}(\mathrm{T}) / \mathrm{Q}$ & 7.74 & 34.37 & 10.32 & 24.11 & 14.26 & 11.33 \\
\hline $\operatorname{CCSD}(\mathrm{T}) /$ aug-Q & 7.92 & 34.27 & 10.27 & 23.35 & 15.47 & 11.34 \\
\hline
\end{tabular}

${ }^{\mathrm{a}}$ Calculated at level $\operatorname{CCSD}(\mathrm{T}) / \mathrm{Q}$.

${ }^{\mathrm{b}} \mathrm{R} 1=\mathrm{X} \cdots \mathrm{H}_{3}^{+} \rightarrow \mathrm{X}+\mathrm{H}_{3}^{+}$and $\mathrm{R} 2=\mathrm{X} \cdots \mathrm{H}_{3}^{+} \rightarrow \mathrm{XH}^{+}+\mathrm{H}_{2}$.

and $\mathrm{HOC}^{+}$could be at least as efficient as the one of $\mathrm{XH}_{3}^{+}$.

(3) For $\mathrm{HNN}^{+}$the situation is closer to that of $\mathrm{HOC}^{+}$but with an inversion of the preference for the dissociative reaction only for xenon: $\mathrm{Ar}$ and $\mathrm{Kr}$ prefer to dissociate through the R1 mechanism, whereas xenon dissociates through the $\mathrm{R} 2$ route. The trend is the same, that is, an increase of the binding energies relative to $\mathrm{R} 1$ dissociation and a decrease for those relative to R2 when going from $\mathrm{Ar}$ to $\mathrm{Xe}$, with a crossing of the values for $\mathrm{Xe}$ (although the energy difference between two routes is much smaller than for $\left.\mathrm{HOC}^{+}\right)$. According to the DFT method (not shown), $\mathrm{XeHNN}^{+}$dissociates through R1, whereas for all the other post HF methods, it prefers R2. Similar to $\mathrm{KrHOC}^{+}$, this shows that high level methods are needed to describe these rather weakly bonded complexes.

\section{BONDING PICTURES IN THE NOBLE GAS COMPLEXES}

Even though, most of the time, the fragments interacting in the complexes can be identified from their preferred dissociation mechanism, a better understanding of bonding pictures can be obtained using both the topological analysis of the electron localization function (ELF) $)^{25-27}$ and the quantum theory of atoms in molecules (QTAIM). ${ }^{28,29}$ As these methodologies have been widely discussed in the literature, they are only recalled in Appendix A. Introduced ${ }^{30}$ by Bader and Stephens and later revisited ${ }^{31}$ by Fradera et al., the delocalization index (DI) is a measure of the electron-sharing between two atoms and can be compared to other bond order indices. The relative percentage of the two resonance structures Ia and $\mathrm{Ib}$, respectively, $\left[\mathrm{X}+\mathrm{ion}^{+}\right]$and $\left[\mathrm{X}-\mathrm{H}^{+}+\right.$neutral $]$, has been evaluated using the DI of protonated bonds. For example, in the case of $\mathrm{X}-\mathrm{H}_{3} \mathrm{O}^{+}$complexes, Ia and $\mathrm{Ib}$ are calculated as follows:

$$
I_{a}=100\left(\frac{D I_{O H_{x}}}{D I_{O H_{x}}+D I_{X H_{x}}}\right) \text { and } \mathrm{I}_{b}=100-\mathrm{I}_{a} .
$$

$\mathrm{H}_{\mathrm{X}}$ is here the hydrogen located in front of the noble gas. In this work, these results have also provided a rationale about the choice of the partition of the systems into fragments to be used for BSSE corrections, especially when there is no straightforward clue, such as for $\mathrm{KrHOC}^{+}$.

The ELF topological analysis applied previously to $\mathrm{X}_{n}\left(\mathrm{H}_{3}^{+}\right)(\mathrm{X}=\mathrm{Ne}, \mathrm{Ar}$, and $\mathrm{Kr} ; \mathrm{n}=1,3)$ complexes has shown the crucial role of the charge transfer from the noble gases toward the $\mathrm{H}_{3}^{+}$cation as a driving force in the bonding along the series. It was also consistent with the increase in the atomic polarizabilities from neon to krypton. ${ }^{3}$ In this work, a net positive charge $\mathrm{q}(\mathrm{X})$ also discloses a charge transfer from the noble gas towards the cation $\left(\mathrm{H}_{3} \mathrm{O}^{+}, \mathrm{HCO}^{+}\right.$, or $\left.\mathrm{HN}_{2}^{+}\right)$. However, the magnitude of $\mathrm{q}(\mathrm{X})$ remains small $(<0.2 \mathrm{e})$, except for $\mathrm{XeOC}^{+}$ $(0.45 \mathrm{e})$.

The ELF localization domains are displayed in Fig. 3. The ELF population analysis for all $\mathrm{X}-\mathrm{H}_{3} \mathrm{O}^{+}, \mathrm{X}-\mathrm{HCO}^{+}$, $\mathrm{X}-\mathrm{HOC}^{+}$, and $\mathrm{X}-\mathrm{HN}_{2}^{+}$complexes is reported in Tables IVVII, respectively.

As observed in Fig. 3 and Table IV, the ELF topology of $\mathrm{X}-\mathrm{H}_{3} \mathrm{O}^{+}$complexes shows two well-separated domains. The first one corresponds to the neutral $X$ noble gas $[q(X)$ remaining always lower than 0.1 electron]; it splits into a core basin $\mathrm{C}(\mathrm{X})$ and valence basins $\mathrm{V}(\mathrm{X})$. The second domain corresponds to $\mathrm{H}_{3} \mathrm{O}^{+}$where one $\mathrm{O}-\mathrm{H}$ bond viewed as the protonated $\mathrm{V}\left(\mathrm{H}_{\mathrm{X}}, \mathrm{O}\right)$ topological basin is stretched toward the noble gas. The population of this latter basin was found to be lower than 1.5 electrons, whereas the other $\mathrm{V}(\mathrm{O}, \mathrm{H})$ populations remain close to 2 electrons. It should be noted that no covalent character was identified for the $\mathrm{X}-\mathrm{H}_{3} \mathrm{O}^{+}$interaction since there are no disynaptic basins located between $\mathrm{X}$ and $\mathrm{H}$. It is fully consistent with a large weight of around $75 \%$ for Ia in all these complexes. Thus, it gives a better understanding of the fragmentation used for the BSSE corrections for which the R2 route is energetically preferred.

The topological analysis of $\mathrm{XHCO}^{+}$complexes (Table V) shows a very similar pattern to that of $\mathrm{H}_{3} \mathrm{O}^{+}$complexes, i.e., two well-separated domains around the noble gas and the $\mathrm{HCO}^{+}$ion. Previously, the population of the protonated $\mathrm{V}\left(\mathrm{H}_{\mathrm{X}}\right.$, C) bonding basin remains lower than 2 electrons for all noble gases. The $\mathrm{I}_{a}$ and $\mathrm{I}_{b}$ weights have been found to be quite similar for both $\mathrm{XH}_{3} \mathrm{O}^{+}$and $\mathrm{XHCO}^{+}$complexes. This confirms again the validity of the fragmentation into the noble gas and $\mathrm{HCO}^{+}$moieties used for the BSSE corrections.

Except for $\mathrm{ArHOC}^{+}$showing a very similar topology to other Ar species $\left(\mathrm{I}_{a}>\mathrm{I}_{b}\right)$, the bonding picture of $\mathrm{XHOC}^{+}$ complexes differs from previous compounds (see Table VI). First, the charge $q(X)$ increases drastically from 0.1 e (Ar) to $0.45 \mathrm{e}(\mathrm{Xe})$. This is in agreement with the increase of the weight of $[\mathrm{X}-\mathrm{H}]^{+}\left(\mathrm{I}_{b}\right)$ in $\mathrm{Kr}$ and Xe complexes (see Tables $\mathrm{V}$ and VI). The ELF topology of $\mathrm{KrHOC}^{+}$undergoes a clear modification since the $\mathrm{V}\left(\mathrm{H}_{\mathrm{X}}, \mathrm{O}\right)$ basin splits into non-bonding basins $\mathrm{V}(\mathrm{H})$ and $\mathrm{V}(\mathrm{O})$. Thus, the weights of $\mathrm{I}_{a}$ and $\mathrm{I}_{b}$ configurations become very similar in agreement with the practically 


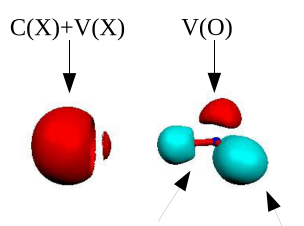

$\mathrm{V}(\mathrm{Hx}, \mathrm{O}) \quad \mathrm{V}(\mathrm{H}, \mathrm{O})$
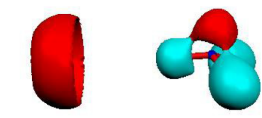

$\mathrm{KrH}_{3} \mathrm{O}^{+}$

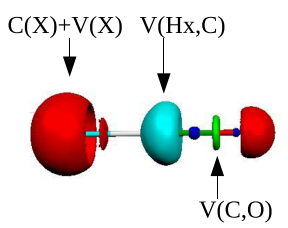

$\mathrm{KrHCO}^{+}$
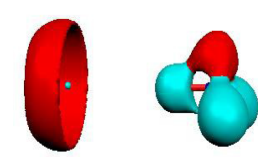

$\mathrm{XeH}_{3} \mathrm{O}^{+}$

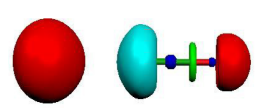

$\operatorname{ArHCO}^{+}$

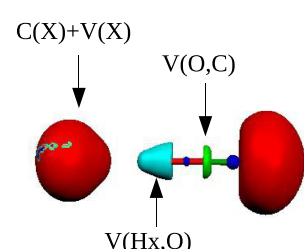

ArHOC

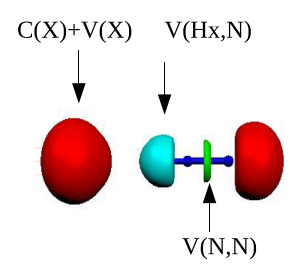

$\operatorname{ArHNN}^{+}$

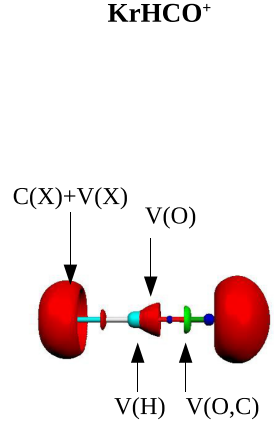

$\mathrm{KrHOC}^{+}$

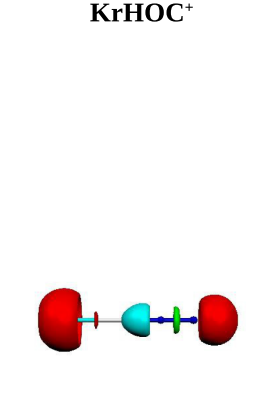

$\mathrm{KrHNN}^{+}$

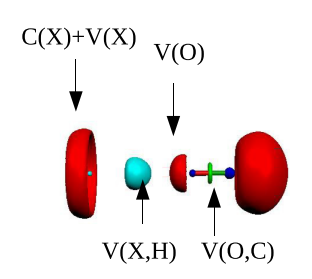

ХeHOC $^{+}$
FIG. 3. View of the electron localization function (ELF $=0.85$ ) isosurfaces (top to bottom) for $\mathrm{X}_{-} \mathrm{H}_{3} \mathrm{O}^{+}$, $\mathrm{X}-\mathrm{HCO}^{+}, \mathrm{X}-\mathrm{HOC}^{+}$, and X-HNN ${ }^{+}$. Color code: magenta: core basins, red: non-bonding basins, green: bonding basins, light blue: protonated basins.

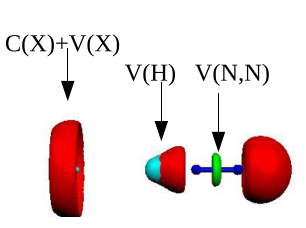

$\mathrm{XeHNN}^{+}$ equal binding energies of 15.5 and $15.2 \mathrm{kcal} / \mathrm{mol}$, respectively, obtained from the dissociation R1 and R2 routes. For XeHOC ${ }^{+}$, the $\mathrm{V}\left(\mathrm{H}_{\mathrm{X}}, \mathrm{O}\right)$ basin disappears in favor of a new disynaptic protonated $\mathrm{V}(\mathrm{H}, \mathrm{X})$ basin. Consequently, the weight of $\mathrm{I}_{b}$ becomes larger than Ia in agreement with the binding energies, respectively, obtained from R1 $(24.6 \mathrm{kcal} / \mathrm{mol})$ and R2 $(7.1 \mathrm{kcal} / \mathrm{mol})$ routes.

TABLE IV. ELF population analysis of $\mathrm{X}_{-} \mathrm{H}_{3} \mathrm{O}^{+}(\mathrm{X}=\mathrm{Ar}, \mathrm{Kr}$, and $\mathrm{Xe})$. Populations of basins and QTAIM charges are in electrons. ${ }^{\mathrm{a}}$

\begin{tabular}{lccccc}
\hline \hline $\mathrm{X}-\mathrm{H}_{3} \mathrm{O}^{+}$ & $\mathrm{C}(\mathrm{X})+\mathrm{V}(\mathrm{X})$ & $\mathrm{V}\left(\mathrm{H}_{\mathrm{X}}, \mathrm{O}\right)$ & $\mathrm{q}(\mathrm{X})$ & $\mathrm{Ia}$ & $\mathrm{Ib}$ \\
\hline $\mathrm{Ar}-\mathrm{H}_{3} \mathrm{O}^{+}$ & 17.96 & 0.93 & 0.04 & 80 & 20 \\
$\mathrm{Kr}-\mathrm{H}_{3} \mathrm{O}^{+}$ & 35.94 & 1.29 & 0.06 & 76 & 24 \\
$\mathrm{Xe}_{-} \mathrm{H}_{3} \mathrm{O}^{+}$ & 25.91 & 1.23 & 0.09 & 74 & 26 \\
$\mathrm{H}_{3} \mathrm{O}^{+}$ & $\cdots$ & 1.86 & & & \\
\hline
\end{tabular}

$\overline{{ }^{a} \text { The } 28 \text { innermost electrons of Xe are not treated explicitly but through an effective core }}$ potential.
Protonated $\mathrm{N}_{2}$, though isoelectronic with protonated $\mathrm{CO}$ isomers, offers another situation. For $\mathrm{XHN}_{2}^{+}$complexes (see Table VII), two well-separated domains are observed for $\mathrm{Ar}$ and $\mathrm{Kr}$. The first domains contain the noble gas basins whereas the others are distributed over the $\mathrm{HN}_{2}^{+}$cation. Thus, the weight $\mathrm{I}_{a}$ remains larger than $\mathrm{I}_{b}$. By contrast, the $\mathrm{XeHN}_{2}^{+}$bonding picture looks like $\mathrm{KrHOC}^{+}$since the protonated $\mathrm{V}\left(\mathrm{H}_{\mathrm{X}}\right.$,

TABLE V. ELF population analysis of $\mathrm{X}-\mathrm{HCO}^{+}(\mathrm{X}=\mathrm{Ar}, \mathrm{Kr}$, and $\mathrm{Xe})$. Populations of basins and QTAIM charges are in electrons. ${ }^{\mathrm{a}}$

\begin{tabular}{lccccc}
\hline \hline $\mathrm{X}-\mathrm{HCO}^{+}$ & $\mathrm{C}(\mathrm{X})+\mathrm{V}(\mathrm{X})$ & $\mathrm{V}\left(\mathrm{H}_{\mathrm{X}}, \mathrm{C}\right)$ & $\mathrm{q}(\mathrm{X})$ & $\mathrm{Ia}$ & $\mathrm{Ib}$ \\
\hline $\mathrm{Ar}-\mathrm{HCO}^{+}$ & 17.96 & 2.36 & 0.04 & 86 & 14 \\
$\mathrm{Kr}_{-}-\mathrm{HCO}^{+}$ & 35.93 & 2.38 & 0.07 & 82 & 18 \\
$\mathrm{Xe}_{-}-\mathrm{HCO}^{+}$ & 25.90 & 2.39 & 0.10 & 79 & 21 \\
$\mathrm{HCO}^{+}$ & & 2.21 & & & \\
\hline
\end{tabular}

$\overline{{ }^{a}}$ The 28 innermost electrons of $\mathrm{Xe}$ are not treated explicitly but through an effective core potential. 
TABLE VI. ELF population analysis of $\mathrm{X}-\mathrm{HOC}^{+}(\mathrm{X}=\mathrm{Ar}, \mathrm{Kr}$, and $\mathrm{Xe})$. Populations of basins and QTAIM charges are in electrons. ${ }^{\mathrm{a}}$

\begin{tabular}{lcccccccc}
\hline \hline $\mathrm{X}_{-} \mathrm{HOC}^{+}$ & $\mathrm{C}(\mathrm{X})+\mathrm{V}(\mathrm{X})$ & $\mathrm{V}\left(\mathrm{H}_{\mathrm{X}}, \mathrm{O}\right)$ & $\mathrm{V}\left(\mathrm{H}_{\mathrm{X}}\right)$ & $\mathrm{V}(\mathrm{O})$ & $\mathrm{V}\left(\mathrm{H}_{\mathrm{X}}, \mathrm{X}\right)$ & $\mathrm{q}(\mathrm{X})$ & $\mathrm{I}_{a}$ & $\mathrm{I}_{b}$ \\
\hline $\mathrm{Ar}-\mathrm{HOC}^{+}$ & 17.90 & 2.42 & $\ldots$ & $\ldots$ & $\ldots$ & 0.10 & 61 & 39 \\
$\mathrm{Kr}_{-} \mathrm{HOC}^{+}$ & 35.85 & $\ldots$ & 0.25 & 4.86 & $\ldots$ & 0.15 & 52 & 48 \\
${\mathrm{Xe}-\mathrm{HOC}^{+}}^{24.27}$ & $\ldots$ & $\ldots$ & 4.52 & 1.81 & 0.45 & 24 & 76 \\
$\mathrm{HOC}^{+}$ & & 2.32 & & & & & & \\
\hline
\end{tabular}

$\overline{{ }^{a} \text { The } 28 \text { innermost electrons of Xe are not treated explicitly but through an effective core }}$ potential.

TABLE VII. ELF population analysis of $\mathrm{X}-\mathrm{HNN}^{+}(\mathrm{X}=\mathrm{Ar}, \mathrm{Kr}$, and $\mathrm{Xe})$. Populations of basins and QTAIM charges are in electrons. ${ }^{\mathrm{a}}$

\begin{tabular}{|c|c|c|c|c|c|c|c|}
\hline X-HNN ${ }^{+}$ & $\mathrm{C}(\mathrm{X})+\mathrm{V}(\mathrm{X})$ & $\mathrm{V}\left(\mathrm{H}_{\mathrm{X}}, \mathrm{N}\right)$ & $\mathrm{V}\left(\mathrm{H}_{\mathrm{X}}\right)$ & $\mathrm{V}(\mathrm{N})$ & $q(X)$ & $\mathrm{I}_{a}$ & $\mathrm{I}_{b}$ \\
\hline $\mathrm{Ar}-\mathrm{X}-\mathrm{HNN}^{+}$ & 17.93 & 2.74 & $\ldots$ & $\ldots$ & 0.07 & 73 & 27 \\
\hline $\mathrm{Kr}-\mathrm{X}-\mathrm{HNN}^{+}$ & 35.88 & 2.79 & $\ldots$ & $\ldots$ & 0.12 & 68 & 32 \\
\hline $\mathrm{Xe}-\mathrm{X}-\mathrm{HNN}^{+}$ & 25.82 & $\ldots$ & 0.33 & 2.49 & 0.18 & 35 & 65 \\
\hline $\mathrm{HN}_{2}^{+}$ & & 2.60 & & & & & \\
\hline
\end{tabular}

${ }^{\text {a The }} 28$ innermost electrons of Xe are not treated explicitly but through an effective core potential.

$\mathrm{N})$ basin splits into $\mathrm{V}\left(\mathrm{H}_{\mathrm{X}}\right)$ and $\mathrm{V}(\mathrm{N})$ valence basins. The weight Ia $(35 \%)$ remains smaller than $\mathrm{I}_{b}(65 \%)$, again in accordance with the preferred dissociation mechanism (see Table III).

\section{RATE CONSTANTS OF THE RADIATIVE ASSOCIATIONS}

The formation of all complexes occurs without an activation barrier. The rate constants of these radiative associations are reported in Tables VIII-X (for $\mathrm{Ar}, \mathrm{Kr}$, and Xe, respectively) for temperatures in the range of $10-100 \mathrm{~K}$, which includes typical temperature interval $(30-100 \mathrm{~K})$ in the protosolar nebula. ${ }^{32}$ All rates present similar variations with the temperature, i.e., a maximum around $60 \mathrm{~K}$.

Regarding Ar complexes with the four different ions, the rates stay close to the value $0.5 \times 10^{-18} \mathrm{~cm}^{3} \mathrm{~s}^{-1}$ obtained for $\mathrm{H}_{3}^{+}$, within one order of magnitude, with a small advantage to $\mathrm{ArHOC}^{+}$whose higher binding energy gives a formation rate going up to $1 \times 10^{-18} \mathrm{~cm}^{3} \mathrm{~s}^{-1}$. Likewise, the maximum rate constants of $\mathrm{Kr}$ complexes are in between $0.4 \times 10^{-18}$ and

TABLE VIII. Rate constants for the radiative association of Ar with protonated ions in $10^{-18} \mathrm{~cm}^{3} \mathrm{~s}^{-1}$ as a function of $\mathrm{T}(\mathrm{K})$.

\begin{tabular}{lccccc}
\hline \hline $\mathrm{T}(\mathrm{K})$ & $\mathrm{ArH}_{3}^{+}$ & $\mathrm{ArH}_{3} \mathrm{O}^{+}$ & $\mathrm{ArHCO}^{+}$ & ArHOC $^{+}$ & ArHNN $^{+}$ \\
\hline 10 & 0.33 & 0.16 & 0.09 & 0.68 & 0.33 \\
20 & 0.43 & 0.22 & 0.11 & 0.94 & 0.45 \\
30 & 0.49 & 0.26 & 0.13 & 1.11 & 0.52 \\
40 & 0.52 & 0.28 & 0.14 & 1.21 & 0.57 \\
50 & 0.53 & 0.29 & 0.15 & 1.25 & 0.58 \\
60 & 0.53 & 0.29 & 0.14 & 1.25 & 0.58 \\
70 & 0.52 & 0.28 & 0.14 & 1.22 & 0.56 \\
80 & 0.50 & 0.27 & 0.13 & 1.18 & 0.54 \\
90 & 0.48 & 0.26 & 0.13 & 1.13 & 0.52 \\
100 & 0.47 & 0.25 & 0.12 & 1.08 & 0.49 \\
\hline \hline
\end{tabular}

TABLE IX. Rate constants for the radiative association of $\mathrm{Kr}$ with protonated ions in $10^{-17} \mathrm{~cm}^{3} \mathrm{~s}^{-1}$ as a function of $\mathrm{T}(\mathrm{K})$.

\begin{tabular}{lccccc}
\hline \hline $\mathrm{T}(\mathrm{K})$ & $\mathrm{KrH}_{3}^{+}$ & $\mathrm{KrH}_{3} \mathrm{O}^{+}$ & $\mathrm{KrHCO}^{+}$ & $\mathrm{KrHOC}^{+}$ & $\mathrm{KrHNN}^{+}$ \\
\hline 10 & 1.75 & 0.019 & 0.010 & 0.26 & 0.12 \\
20 & 2.43 & 0.026 & 0.019 & 0.35 & 0.17 \\
30 & 2.91 & 0.031 & 0.021 & 0.42 & 0.20 \\
40 & 3.23 & 0.034 & 0.024 & 0.47 & 0.21 \\
50 & 3.42 & 0.035 & 0.026 & 0.50 & 0.22 \\
60 & 3.50 & 0.035 & 0.026 & 0.51 & 0.22 \\
70 & 3.50 & 0.034 & 0.024 & 0.52 & 0.21 \\
80 & 3.44 & 0.033 & 0.023 & 0.51 & 0.21 \\
90 & 3.35 & 0.021 & 0.021 & 0.51 & 0.20 \\
100 & 3.24 & 0.020 & 0.029 & 0.49 & 0.19 \\
\hline \hline
\end{tabular}

TABLE X. Rate constants for the radiative association of Xe with protonated ions in $10^{-17} \mathrm{~cm}^{3} \mathrm{~s}^{-1}$ as a function of $\mathrm{T}(\mathrm{K})$.

\begin{tabular}{lccccc}
\hline \hline $\mathrm{T}(\mathrm{K})$ & $\mathrm{XeH}_{3}^{+}$ & $\mathrm{XeH}_{3} \mathrm{O}^{+}$ & $\mathrm{XeHCO}^{+}$ & $\mathrm{XeHOC}^{+}$ & $\mathrm{XeHNN}^{+}$ \\
\hline 10 & 4.90 & 0.064 & 0.031 & 0.44 & 0.29 \\
20 & 6.96 & 0.087 & 0.042 & 0.61 & 0.40 \\
30 & 8.36 & 0.10 & 0.050 & 0.74 & 0.47 \\
40 & 9.24 & 0.11 & 0.056 & 0.82 & 0.52 \\
50 & 9.72 & 0.12 & 0.059 & 0.89 & 0.55 \\
60 & 9.87 & 0.12 & 0.061 & 0.93 & 0.57 \\
70 & 9.73 & 0.11 & 0.062 & 0.94 & 0.57 \\
80 & 9.55 & 0.11 & 0.061 & 0.94 & 0.56 \\
90 & 9.23 & 010 & 0.060 & 0.93 & 0.54 \\
100 & 8.83 & 0.099 & 0.059 & 0.91 & 0.52 \\
\hline \hline
\end{tabular}

$5 \times 10^{-18} \mathrm{~cm}^{3} \mathrm{~s}^{-1}$, in agreement with their relative binding energies. The efficiency of the reactions for Xe complexes increases again with the binding energy, starting from $0.6 \times$ $10^{-18}$ up to almost $10 \times 10^{-18} \mathrm{~cm}^{3} \mathrm{~s}^{-1}$.

Comparing these results with the rate constants of the $\mathrm{H}_{3}^{+}$complexes, we observe that those of $\mathrm{Ar}$ complexes are in the same order of magnitude as $\mathrm{ArH}_{3}^{+}$, whereas the rates of $\mathrm{Kr}$ complexes are lower than $\mathrm{KrH}_{3}^{+}$, by almost one order of magnitude for $\mathrm{KrN}_{2} \mathrm{H}^{+}$and $\mathrm{KrHOC}^{+}$and even two for $\mathrm{KrH}_{3} \mathrm{O}^{+}$ and $\mathrm{KrHCO}^{+}$; the same behavior is observed for Xe complexes. However, it has to be noted that all the rates concerning $\mathrm{Kr}$ and Xe complexes are higher than those of Ar complexes and that even the smallest rates of $\mathrm{Kr}$ and $\mathrm{Xe}$ complexes can compare with those of $\mathrm{ArH}_{3}^{+}$. Thus, they all can be considered as quite efficient in terms of radiative association reactions.

It has also to be reminded that, since the approach applied treats the complexes as pseudo-diatomic systems, the accuracy of the rate constant calculations is lesser for the ions having linear geometry than for $\mathrm{H}_{3}^{+}$that has a more sphere like symmetry.

\section{CONCLUDING REMARKS}

An extensive study of the complexes issued from the trapping of the noble gases by the $\mathrm{H}_{3}^{+}$ion had indicated that such complexes were far more stable than expected. The important result of the present study is that this property appears to generalize to other protonated ions, in particular ions issued 
from common interstellar molecules as $\mathrm{H}_{2} \mathrm{O}, \mathrm{CO}$, and $\mathrm{N}_{2}$ which, through interaction with $\mathrm{H}_{3}^{+}$, give $\mathrm{H}_{3} \mathrm{O}^{+}, \mathrm{HCO}^{+}, \mathrm{HOC}^{+}$, and $\mathrm{N}_{2} \mathrm{H}^{+}$. Apart from $\mathrm{H}_{3} \mathrm{O}^{+}$, all of these complexes have a linear structure, the noble gas pointing to the hydrogen side. Although all these well-defined complexes are stabilized by long-range interactions, they do not belong to the same family. The topological analysis of the electron localization function shows that $\mathrm{XH}_{3} \mathrm{O}^{+}, \mathrm{XHCO}^{+}, \mathrm{ArHOC}^{+}, \mathrm{ArN}_{2} \mathrm{H}^{+}$, and $\mathrm{KrN}_{2} \mathrm{H}^{+}$complexes can be described as (X $\cdots$ ion) systems, whereas $\mathrm{XeHOC}^{+}$and $\mathrm{XeN}_{2} \mathrm{H}^{+}$are better described as $\left(\mathrm{XH}^{+} \ldots\right.$ neutral $)$ systems, the case of $\mathrm{KrHOC}^{+}$remaining unclear. The partitioning so obtained is at the basis of a reliable evaluation of the BSSE corrections necessary to determine accurate geometries and rotational constants in view of the search for these species at radio wavelengths (in the laboratory or in space). However, the trapping ability of these ions had also to be investigated by evaluating their formation reactions rates. A fully $a b$ initio approach has been applied in the framework of the one-dimensional reaction coordinate approximation. According to our results, the noble gas complexes with the ions obtained by the destructive reactions of $\mathrm{H}_{3}^{+}$have rate constants in the range of $10^{-19}$ to $10^{-17}$ $\mathrm{cm}^{3} \mathrm{~s}^{-1}$ which can be considered fairly efficient values for radiative association reactions. Therefore, the destruction of $\mathrm{H}_{3}^{+}$also forms ions which have the capacity to trap noble gases as well.

From an astrochemical point of view, these results support the hypothesis that the heavy noble gases could be sequestrated by protonated species $\left(\mathrm{H}_{3}^{+}\right.$or/and daughter molecules) in the gas phase of the protosolar nebula. These properties would then prevent the noble gases from condensation or incorporation in the ices formed at large heliocentric distances during the cooling of the protosolar nebula. The trapping ability of the products formed by the destruction of $\mathrm{H}_{3}^{+}$ions remains preserved since this mechanism leads to the same number of protonated trapping agents at least as efficient as the parent ion $\mathrm{H}_{3}^{+}$. These processes could explain the noble gas depletion in the planetesimals which, later on, agglomerated to form Titan. ${ }^{4}$

They are also relevant to the determination of the origin of comets since a larger noble gas deficiency in a comet may imply that this body agglomerated from grains formed at larger heliocentric distances, where the trapping efficiency by protonated species increases. The in situ measurements ${ }^{33}$ in comet 67P/Churyumov-Gerasimenko made by the ROSINA mass spectrometer aboard the Rosetta spacecraft give ${ }^{36} \mathrm{Ar} / \mathrm{H}_{2} \mathrm{O}$ $\sim 0.1-2.3 \times 10^{-5}$. This value, compared with ${ }^{36} \mathrm{Ar} / \mathrm{H}_{2} \mathrm{O} \sim 5.9$ $\times 10^{-3}$ in the protosolar nebula, ${ }^{34}$ indicates a significant though moderate depletion, as expected from our model. The future measurement of $\mathrm{Kr}$ and $\mathrm{Xe}$ abundances in long period comets, such as C/1995 O1 (Hale-Bopp), will be needed to assess the validity of our model. On the other hand, similar determinations in short period comets, such as comet 67P/ChuryumovGerasimenko, may not display values representative of those acquired at their formation epoch in the protosolar nebula. This alteration could result from the progressive devolatilization of these comets during their multiple orbits with perihelions close to the Sun.
Moreover, the mechanism proposed here is valid in the ISM where $\mathrm{H}_{3}^{+}$should be even more abundant than in the protosolar nebula. However, it has to be reminded that the $\mathrm{H}_{3}^{+}$ abundance in the ISM is poorly constrained compared to those of $\mathrm{HCO}^{+}$and the other ions; this results from the fact that the $\mathrm{H}_{3}^{+}$abundance must be determined at infrared wavelengths, a difficult task to perform compared to the case of the other ions whose abundances can be fairly easily quantified in the radio domain.

\section{ACKNOWLEDGMENTS}

This work was supported by CNRS national program PCMI (Physics and Chemistry of the Interstellar Medium) and COST Action CM 1401, "Our Astrochemical History." We acknowledge computational resources from CCIN2P3 in Villeurbanne. O.M. acknowledges support from CNES. This work has been partly carried out, thanks to the support of the A*MIDEX project (No. ANR-11-IDEX-0001-02) funded by the "Investissements d'Avenir" French Government program, managed by the French National Research Agency (ANR).

\section{APPENDIX A: QUANTUM CHEMICAL TOPOLOGY}

The methodology lies on the analysis of the gradient field of a scalar function by applying the theory of dynamical systems. The latter provides a partitioning of the molecular space into non-overlapping volumes (basins) localized around maxima of the scalar function and separated by zero flux surfaces. In the atoms in molecular theory (QTAIM), the function is the electron density. Each atom of a molecule corresponds to a basin and the integration of the electron density over the basin volume provides an atomic population. The atomic charge of a topological atom $\Omega, \mathrm{q}(\Omega)$, is calculated by subtracting the atomic population from the atomic number, $Z(\Omega)$. If effective core potentials (ECPs) are used for some atoms (case of Xe species), the calculation of their atomic charge involves Zeff, the charge of the inner-core. If the scalar function is the electron localization function (ELF) of Becke and Edgecombe, atomic and non-atomic basins are found. The topology of the function can be related to chemical concepts issued from the Lewis theory. The core basins $(\mathrm{Z}>2)$ are located at nuclear centers, whereas the valence basins are located in the remaining space: monosynaptic basins, labeled $\mathrm{V}(\mathrm{X})$, usually correspond to the lone-pair regions of $\mathrm{X}$ atoms while disynaptic basins, labeled $\mathrm{V}(\mathrm{X}, \mathrm{Y})$, correspond to twocenter $\mathrm{X}-\mathrm{Y}$ bonds. Disynaptic basins $\mathrm{V}(\mathrm{H}, \mathrm{Y})$ are termed as protonated basins. The integration of the total electron density over the basin volume provides a covalent bond population for $\mathrm{V}(\mathrm{X}, \mathrm{Y})$ basins while lone-pair populations can be obtained for $\mathrm{V}(\mathrm{X})$ basins.

\section{APPENDIX B: QUANTUM DYNAMIC PROCEDURE}

We used a complete $a b$ initio method ${ }^{35-37}$ to determine rate constants, in which they are calculated by averaging over the cross sections with a Maxwellian velocity distribution at temperature $\mathrm{T}$,

$$
\mathrm{k}(\mathrm{T})=\langle\mathrm{v}, \sigma(\mathrm{v})\rangle,
$$


as proposed ${ }^{38}$ by Bacchus-Montabonel et al. The quantum expression of the cross section at a given relative collision energy $\mathrm{E}$ of the colliding fragments is given by

$$
\sigma(E)=\sum_{J} \sigma_{J}(E)
$$

with

$$
\sigma_{J}(E)=\sum_{v^{\prime} J^{\prime}} \frac{64}{3} \frac{\pi^{5}}{c^{3}} \frac{g}{2 \mu E} v_{E, v^{\prime} J^{\prime}}^{3} S_{J J^{\prime}} M_{E J, v^{\prime} J^{\prime}}^{2},
$$

where $\mu$ is the reduced mass, $g$ is a parameter accounting for the degeneracy of the electronic state (here $g=1$ ), $S_{J J^{\prime}}$ are the Höln-London coefficients characteristic of the $\mathrm{J} \mathrm{J}^{\prime}$ pair of rotational levels, and $M_{E J, v^{\prime} J^{\prime}}^{2}$ is the free-bound transition moment matrix element of the dipole moment $\mathrm{D}(\mathrm{R})$ between the energy normalized function $f_{E J}$ of the continuum and the bound rovibrational function $\phi_{v^{\prime} J^{\prime}}$ for the same potential. In this expression, $v_{E, v^{\prime} J^{\prime}}$ is the emitted photon frequency corresponding to the energy difference between the continuum level of energy $\mathrm{E}$ and the rovibrational bound state of energy $\mathrm{E}_{v^{\prime} J^{\prime}}$ is given by

$$
\mathrm{E}=\mathrm{h} v_{\mathrm{v}^{\prime} \mathrm{J}^{\prime}}=\mathrm{E}-\mathrm{E}_{\mathrm{v}^{\prime} \mathrm{J}^{\prime}} .
$$

For diatomic molecules, the rovibrational bound states and corresponding free-bound dipole transition moments can be evaluated so that rate constants may be calculated with a quantum chemical treatment. This approach may be extended for larger molecules in the framework of the one-dimensional reaction coordinate approximation in which the complex can be divided into two fragments and potential energy is optimized for each distance between the fragments. Therefore, in this work, we considered the formation of noble gas complexes to occur along the [ion $\cdots$ noble gas] reaction coordinate, in its electronic ground state potential energy curve, as no excited states could be involved in the process. Although this model cannot take into account all degrees of freedom of the complex, it is shown to give reliable results even in the case of two molecular fragments $\left(\mathrm{CH}_{3}^{+}\right.$and $\left.\mathrm{H}_{2}\right){ }^{38}$

${ }^{1}$ H. B. Niemann, S. K. Atreya, and S. J. Bauer, Nature 438, 779 (2005).

${ }^{2}$ F. Pauzat and Y. Ellinger, J. Chem. Phys. 127, 014308 (2007).

${ }^{3}$ F. Pauzat, Y. Ellinger, J. Pilmé, and O. Mousis, J. Chem. Phys. 130, 174313 (2009).

${ }^{4}$ O. Mousis, F. Pauzat, Y. Ellinger, and C. Ceccarelli, Astrophys. J. 673, 637 (2008).
${ }^{5}$ O. Mousis, U. Marboeuf, J. I. Lunine et al., Astrophys. J. 696, 1348 (2009).

${ }^{6}$ F. Pauzat, Y. Ellinger, O. Mousis, M. Ali-Dib, and O. Ozgurel, Astrophys. J. 777, 29 (2013).

${ }^{7}$ D. Buhl and L. E. Snyder, Nature 228, 267 (1970).

${ }^{8}$ R. C. Woods, T. A. Dixon, R. J. Saykally, and P. G. Szanto, Phys. Rev. Lett. 35, 1269 (1975).

${ }^{9}$ B. E. Turner, Astrophys. J. 193, L83 (1974).

${ }^{10}$ S. Green, J. A. Montgomery, Jr., and P. Thaddeus, Astrophys. J. 193, L89 (1974).

${ }^{11}$ R. C. Woods, C. S. Gudeman, R. L. Dickman, P. F. Goldsmith, G. R. Huguenin, W. M. Irvine, A. Hjalmarson, L.-A. Nyman, and H. Olofsson, Astrophys. J. 270, 583 (1983).

${ }^{12}$ L. M. Ziurys and A. J. Apponi, Astrophys. J. 455, L73 (1995).

${ }^{13}$ A. A. Stark and R. S. Wolff, Astrophys. J. 229, 118 (1979).

${ }^{14}$ R. Mauersberger and C. Henkel, Astron. Astrophys. 245, 457 (1991).

${ }^{15}$ A. Usero, S. Garca-Burillo, A. Fuente, J. Martin-Pintado, and N. J. Rodriguez-Fernandez, Astron. Astrophys. 419, 897 (2004).

${ }^{16}$ J. M. Hollis, E. B. Churchwell, E. Herbst, and F. C. de Lucia, Nature 322, 524 (1986).

${ }^{17}$ A. Wootten, F. Boulanger, M. Bogey, F. Combes, P. J. Encrenaz, M. Gerin, and L. Ziurys, Astron. Astrophys. 166, L15 (1986).

${ }^{18}$ P. Drossart, J.-P. Maillard, J. Caldwell et al., Nature 340, 539 (1989).

${ }^{19}$ T. R. Geballe and T. Oka, Nature 384, 334 (1996).

${ }^{20}$ B. J. McCall, T. R. Geballe, K. H. Hinkle, and T. Oka, Science 279, 1910 (1998).

${ }^{21}$ F. Pauzat, M.-C. Bacchus-Montabonel, Y. Ellinger, and O. Mousis, Astrophys. J. 821, L33 (2016).

${ }^{22}$ M. J. Barlow, B. M. Swinyard, P. J. Owen, J. Cernnicharo, H. L. Gomez, R. J. Ivison, O. Krause, T. L. Lim, M. Matsuura, S. Miller, G. Olofsson, and E. T. Polehampton, Science 342, 1343 (2013).

${ }^{23}$ M. Frisch, G. W. Trucks, H. B. Schlegel, G. E. Scuseria et al., Gaussian 09, Revision D01, Gaussian, Inc., Wallingford, CT, 2009.

${ }^{24}$ S. F. Boys and F. Bernardi, Mol. Phys. 19, 553 (1970).

${ }^{25}$ B. Silvi and A. Savin, Nature 371(6499), 683 (1994).

${ }^{26}$ A. D. Becke and K. E. Edgecombe, J. Chem. Phys. 92, 5397 (1990).

${ }^{27}$ A. Savin, O. Jepsen, J. Flad, O. K. Andersen, H. Preuss, and H. G. von Schnering, Angew. Chem., Int. Ed. Engl. 31(2), 187-188 (1992).

${ }^{28}$ R. F. W. Bader, Chem. Rev. 91(5), 893 (1991).

${ }^{29}$ R. F. W. Bader, Atoms in Molecules: A Quantum Theory (Oxford University Press, New York, 1994).

${ }^{30}$ R. F. W. Bader and M. E. Stephens, J. Am. Chem. Soc. 97, 7391 (1975).

${ }^{31}$ X. Fradera, M. A. Austen, and R. F. W. Bader, J. Phys. Chem. A 103, 304 (1998).

${ }^{32}$ O. Mousis and D. Gautier, Planet. Space Sci. 52, 361 (2004).

${ }^{33}$ H. Balsiger, K. Altwegg, A. Bar-Nun et al., Sci. Adv. 1, e1500377 (2015).

${ }^{34}$ K. Lodders, H. Palme, and H.-P. Gail, in Landolt Börnstein, edited by J. E. Trmper (Springer, Berlin, 2009), p. 560.

${ }^{35}$ B. Zygelman and A. Dalgarno, Astrophys. J. 365, 239 (1990).

${ }^{36}$ P. C. Stancil, J. F. Babb, and A. Dalgarno, Astrophys. J. 414, 672 (1993).

${ }^{37}$ F. A. Gianturco and P. Gori-Giorgi, Astrophys. J. 479, 560 (1997).

${ }^{38}$ M. C. Bacchus-Montabonel, D. Talbi, and M. Persico, J. Phys. B 33, 955 (2000). 